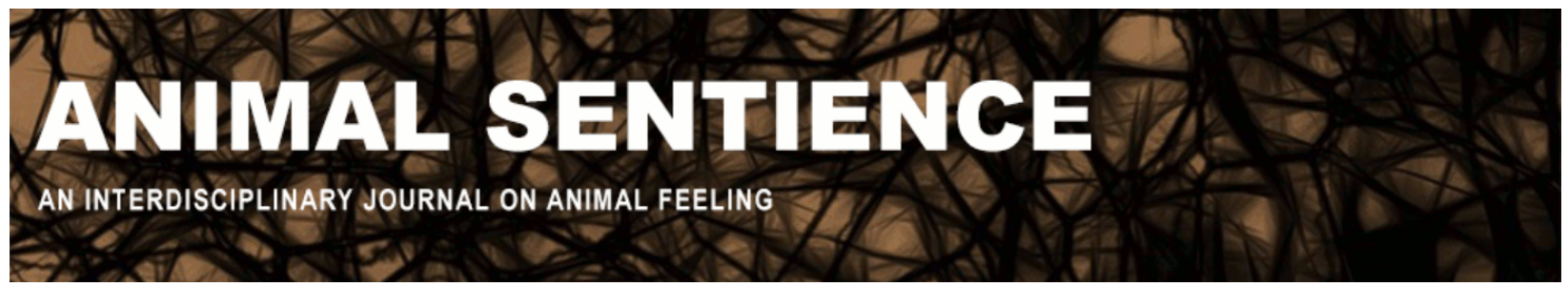

Rowlands, Mark (2016) Feel or perspective?. Animal Sentience 9(9)

DOI: $10.51291 / 2377-7478.1143$

Date of submission: 2016-08-13

Date of acceptance: 2016-08-16

(c) (i)

This article has appeared in the journal Animal

Sentience, a peer-reviewed journal on animal

cognition and feeling. It has been made open access,

free for all, by WellBeing International and deposited

in the WBI Studies Repository. For more information,

please contact

wbisr-info@wellbeingintl.org.

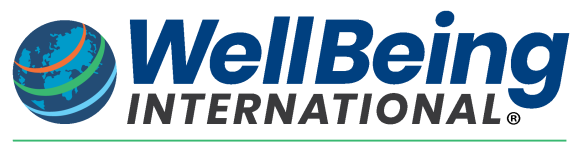

SOLUTIONS FOR PEOPLE, ANIMALS AND ENVIRONMENT 


\title{
Feel or perspective?
}

Commentary on Klein \& Barron on Insect Experience

\author{
Mark Rowlands \\ Department of Philosophy \\ University of Miami
}

\begin{abstract}
The title of Klein \& Barron's well-argued and thought-provoking target article is, "Insects have the capacity for subjective experience." However, they also frame their claim using the term "consciousness," which they seem to take as equivalent to "subjective experience." This assumed equivalence, I shall argue, is problematic in a way that might vitiate their central argument.
\end{abstract}

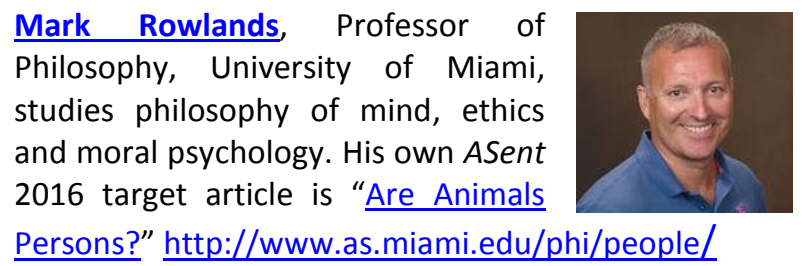

Klein \& Barron (K \& B) are very clear that we should distinguish what they dub "minimal" consciousness from more sophisticated, and therefore more demanding, versions: "We think it is possible to have subjective experience without higher-order thoughts, self-awareness of oneself as a subject, or reportable access to one's own phenomenal states" (2). I agree, strongly. They further note: "Most authors mark off a very basic sense of 'conscious' that refers to the basic capacity to have subjective experience." However, even minimal consciousness - in this sense of subjective experience - straddles two distinct ideas, one corresponding to the idea of experience and the other to that of subjective.

The former is what is often called "phenomenal feel" - feel, for short. An experience is conscious if there is something that it is like to have it. If you have a conscious experience, things seem or feel a certain way to you - and they do so precisely because you are having that experience. I use these terms "seem" or "feel" with some trepidation, since I suspect they house multiple forms of obscurity and ambiguity (see Rowlands 2001), but they are not essential to the problems I shall raise against K \& B's argument. This is because $K \&$ B's focus seems to be on the notion of subjectivity rather than feel. With respect to subjectivity, the idea of a perspective is crucial. An experience of yours is subjective if it is, in principle, the sort of thing that only you can have: you and you alone have access to your experience. The experience, that is, exists from a perspective that you and you alone can adopt.

The ideas of feel and perspective are distinct (Lycan 1996, Kriegel 2005). While it is (probably) true that phenomenal feel entails subjective perspective, the converse entailment is (as we shall see) far more problematic. Perhaps the most significant consideration in 
establishing the distinctness of feel and perspective, however, is that each feature seems to require a different type of explanation. For example, Lycan (1996) has argued that perspective can be best explained in terms of a higher-order experiential model of consciousness, grounded in the idea of one neural mechanism having the function of monitoring the operations of another. A subjective perspective is underwritten by the fact that one and only one mechanism has access to these operations (or, if there is more than one monitoring mechanism, it belongs to the same brain). Even if this were true, however, it would do little to explain phenomenal feel: there is nothing in this account itself that would explain why the discriminations of an internal monitoring mechanism should feel like anything at all.

With this distinction in mind, consider $\mathrm{K} \& \mathrm{~B}^{\prime} \mathrm{s}$ argument. Echoing a tradition that can be traced back to Aristotle's conception of the "locomotive soul," K \& B think of consciousness as intrinsically connected with the capacity for movement. This is not unreasonable. If a creature did not have the capacity to move, the development of consciousness would be evolutionarily useless. The capacity to move, $K \& B$ argue, engenders a specific problem for mobile animals: " $A$ moving animal must disambiguate environmental movement from the sensory input caused by its own motion relative to the environment" (3). It is, they claim, computationally more effective to solve this re-afference problem "once in a unified sensory model." The reason is that, "different senses contribute different information on how the body is moving; thus re-afference can be resolved with greater accuracy and precision by integrating information from multiple senses" (3). In vertebrates, the seat of such integration is, they argue, the superior collicus (SC), which "acts as a point of convergence for spatially structured sensory information, including information about the position, orientation and movement of the body." Processing in the SC creates a "neural model of the mobile animal in space." K \& B then argue that functional analogues of the SC exist in insect brains also. "The CX [central complex] is functionally analogous to the SC in many respects. The CX processes multiple sources of spatial information drawn from different senses to locate the moving animal in space" (7). They conclude: "In summary, there are significant parallels between the functional organization of the insect brain and that of the vertebrate midbrain behavioral core control system. Both systems have specialized regions for processing the position of the moving animals in space" (7). Furthermore: "[P]rocessing of this kind supports the capacity for a subjective experience of the environment" (8).

Although K \& B make it clear that they are interested in consciousness in a "minimal" sense, divorced from higher-order thought or self-awareness, it does seem, by this point, that their conception of consciousness looks rather sophisticated. Indeed, one can't help but suspect that their account assumes the general contours, if not the details, of the more sophisticated conceptions of conscious they were keen to eschew. One, apparently, does not need selfawareness (whatever that means) to be conscious, but one does, apparently, need a "neural model of the mobile animal in space" (4). But why would one think that consciousness - in a minimal sense - has anything essentially to do with the capacity to self-represent or self-locate oneself in space? Why should this be crucial to consciousness rather than to self-awareness?

On this point, $K \& B$ are in danger of falling victim to a dilemma. Recall their original rationale for the importance of movement. Movement engenders a problem: a moving creature must be able to differentiate changes in sensory input caused by self-movement from those caused by environmental movement. But this statement of the problem presupposes that the 
mobile creature already has the ability to detect sensory changes. It might be true that without something like the SC or CX it would not be able to discriminate between changes caused in these two different ways. But the capacity to detect is one thing, the capacity to differentiate what one detects from something else quite another. (I can detect a red wine when it sits in a glass in front of me, and I can do so through multiple sensory means. But I might not be able to differentiate a Saint Chinian from a Faugeres).

The dilemma, then, looks like this. The first horn: If the detection of sensory changes (whether the result of self or environmental movement) is conscious, then the sorts of processes $K \&$ B claim provide the basis of consciousness in mobile creatures cannot really provide this basis. Consciousness has already entered the picture before the (integrating, unifying, etc.) processes $\mathrm{K} \& \mathrm{~B}$ claim are essential to it begin their work. The second horn: Suppose, on the other hand, that the mobile creature's detection of sensory changes is unconscious - there is detection of information but without conscious awareness. If $\mathrm{K} \& \mathrm{~B}$ adopt this route, then there is no reason why the skeptic about consciousness in insects could not say the same of the processes involved in self-location. That is, the skeptic can claim that the "the dynamic and ongoing connection between perception, interoception, associative memory, and motor feedback" (5) takes the form, in insects at least, of non-conscious detection of information. This, then, is the dilemma: either $\mathrm{K} \& \mathrm{~B}^{\prime} \mathrm{s}$ account of consciousness presupposes consciousness or it does not establish the presence of consciousness in insects.

It is no accident, I think, that $K \& B$ end up facing this dilemma. Their real target is the notion of a perspective not the notion of feel. If their arguments work, they might have established that insects have, in their sense, a subjective perspective. But they have not established that things seem or feel any way to insects when they inhabit these perspectives.

\section{References}

Klein, C., \& Barron, A. B. (2016) Insects have the capacity for subjective experience. Animal Sentience 2016.100

Kriegel, U. (2005) Naturalizing subjective character, Philosophy and Phenomenological Research, Vol. 71, No. 1, pp. 23-57

Lycan, W. (1996) Consciousness and Experience (Cambridge, MA: MIT Press)

Rowlands, M. (2001) The Nature of Consciousness (Cambridge: Cambridge University Press) 